OPEN ACCESS

Edited by:

Yuri Agrawal,

Johns Hopkins University, USA

Reviewed by:

Kathleen Cullen,

McGill University, Canada

Sascha Du Lac,

Johns Hopkins University, USA

*Correspondence:

Paul F. Smith

paul.smith@otago.ac.nz

Specialty section:

This article was submitted to

Neuro-otology,

a section of the journal

Frontiers in Neurology

Received: 02 November 2015 Accepted: 09 February 2016

Published: 03 March 2016

Citation:

Smith PF (2016) Age-Related Neurochemical Changes in the Vestibular Nuclei.

Front. Neurol. 7:20.

doi: 10.3389/fneur.2016.00020

\section{Age-Related Neurochemical Changes in the Vestibular Nuclei}

\author{
Paul F. Smith* \\ Department of Pharmacology and Toxicology, School of Medical Sciences and Brain Health Research Centre, University of \\ Otago, Dunedin, New Zealand
}

There is evidence that the normal aging process is associated with impaired vestibulo-ocular reflexes (VOR) and vestibulo-spinal reflexes, causing reduced visual acuity and postural instability. Nonetheless, the available evidence is not entirely consistent, especially with respect to the VOR. Some recent studies have reported that VOR gain can be intact even above 80 years of age. Similarly, although there is evidence for age-related hair cell loss and neuronal loss in Scarpa's ganglion and the vestibular nucleus complex (VNC), it is not entirely consistent. Whatever structural and functional changes occur in the VNC as a result of aging, either to cause vestibular impairment or to compensate for it, neurochemical changes must underlie them. However, the neurochemical changes that occur in the VNC with aging are poorly understood because the available literature is very limited. This review summarizes and critically evaluates the available evidence relating to the noradrenaline, serotonin, dopamine, glutamate, GABA, glycine, and nitric oxide neurotransmitter systems in the aging VNC. It is concluded that, at present, it is difficult, if not impossible, to relate the neurochemical changes observed to the function of specific VNC neurons and whether the observed changes are the cause of a functional deficit in the VNC or an effect of it. A better understanding of the neurochemical changes that occur during aging may be important for the development of potential drug treatments for age-related vestibular disorders. However, this will require the use of more sophisticated methodology such as in vivo microdialysis with single neuron recording and perhaps new technologies such as optogenetics.

Keywords: vestibular nucleus complex, aging, monoamines, glutamate, GABA, nitric oxide

\section{AGE-ASSOCIATED CHANGES IN VESTIBULAR FUNCTION}

Aging in humans has been thought to be associated with an increasing impairment of the vestibuloocular reflexes (VOR) and vestibulo-spinal reflexes, which results in reduced visual acuity and postural instability (1-14). The prevalence of dizziness and vertigo has been estimated at $30 \%$ in people over the age of 60 , and dizziness in the elderly is associated with a high risk of falls (15, 16). Nonetheless, there is disagreement about VOR impairment, in particular. A recent study of the VORs using the video head impulse test (vHIT) for all six semi-circular canals reported that,

\footnotetext{
Abbreviations: 5-HT, 5-hydroxy-tryptamine; AMPA, $\alpha$-amino-3-hydroxyl-5-methyl-4-isoxazole-propionate; GABA, $\gamma$-aminobutyric acid; HPLC, high performance liquid chromatography; NMDA, $N$-methyl-D-aspartate; NO, nitric oxide; VNC, vestibular nucleus complex; VOR, vestibulo-ocular reflex.
} 
although gain decreased with high head velocities, it was largely unaffected in healthy adults in the 80-89 years' age group (17). Similar results have recently been reported by Matiño-Soler et al. (18), who observed that the horizontal VOR gain was stable up until 90 years of age and then decreased thereafter. McGarvie et al. (17) suggested that cerebellar compensation, in the form of VOR plasticity, may be responsible for the preservation of VOR function despite aging. On the other hand, Li et al. (19) reported that horizontal VOR gain remained stable from 26 to 79 years of age and then significantly declined (people over the age of 80 had an approximately eightfold increase in the odds of having a VOR gain $<0.80$ ). Kim and Sharpe (20) also found that the vertical VOR was relatively preserved in the elderly, although vertical smooth pursuit eye movement, eye-head tracking, and VOR cancelation during intentional head movement, were impaired. Studies of perceptual threshold levels related to the horizontal VOR have suggested that there may be little difference between young and older adults (21), although some dynamic visual acuity studies suggest otherwise (22). Otolithic function, evaluated using ocular and cervical vestibular-evoked myogenic potentials (o- and c-VEMPs), has been reported to decline with age (19, 23-26). Vestibulo-sympathetic reflexes have also been reported to be impaired with increasing age, which can lead to an increase in orthostatic hypotension $(27,28)$.

There is increasing evidence that age-related changes in vestibular function result in cognitive deficits (29-31). Cyran et al. (31) studied the functional connectivity of a vestibular cortical network (i.e., the superior, middle, and inferior frontal and temporal gyri, the lingual gyrus, insula, superior and inferior parietal lobe, parietal operculum, posterior cingulate gyrus, cuneus, thalamus, and cerebellar tonsil) in relation to age, using a tensor independent component analysis of fMRI data acquired in response to galvanic vestibular stimulation. They found that the functional connectivity of the network decreased with age, which they suggested was due not to structural deterioration but to functional changes; the somatosensory sensory networks, on the other hand, remained relatively intact. Recently, several large epidemiological studies have implicated vestibular dysfunction in the development of cognitive deficits in elderly humans (29, 30,32 ). Although these data are based on surveys and therefore necessarily correlational in nature, they are consistent with the results of clinical studies in humans [e.g., see Ref. $(33,34)$ for a review] and experimental studies in animals (35-40), which have shown that vestibular dysfunction results in cognitive impairment, especially related to spatial memory.

Age-related vestibular impairment has often been attributed to a degeneration of the peripheral vestibular receptor hair cells or to changes in the number of neurons in Scarpa's ganglion or the brainstem vestibular nucleus complex (VNC). Many studies have reported that the hair cells and their afferent connections decrease with age (41-50). Nonetheless, some studies have found no significant age-related differences in the number of hair cells in the crista ampullaris of aging gerbils (51) or the human utricle (52) and others have found no significant differences in the number of neurons in Scarpa's ganglion $(53,54)$. Neuronal loss has been reported in the human VNC (55-58) and in the VNCs of some animal species [e.g., Ref. (59)]. However, Fernandez et al. (60) could find no significant age-related decrease in the number of neurons in the golden hamster. Johnson and Miquel (61) analyzed the ultrastructure of the rat lateral vestibular nucleus at 4 weeks, 6-8 weeks, 6-8 months, and 18-20 months of age, and found a number of age-related changes that increased in frequency with increasing age, including nuclear membrane invaginations, disorganized endoplasmic reticulum, rod-like nuclear inclusions, and lipofuscin-like cytoplasmic dense bodies. In addition, the oldest age group exhibited axonal degeneration and dendritic swelling. Takeuchi et al. (62) have also reported dystrophic axon terminals in the VNC of 360-day-old gerbils. The cytoplasms were found to contain neurofilaments and vesicles with membranous granular substances. Therefore, it is possible that there is age-related structural deterioration in the VNC even without neuronal loss itself.

In summary, there is increasing evidence that the human VORs are largely intact, at least until approximately 80 years of age. Ocular and cervical vestibular-evoked myogenic potentials (o- and c-VEMPs), on the other hand, appear to decline more obviously with age, and there is epidemiological evidence at least to suggest that any decline in vestibular function with age is associated with cognitive deficits. The evidence relating to structural deterioration of the peripheral hair cells, and neuronal loss in Scarpa's ganglion and the VNC, is divided, although there may be morphological changes in the VNC irrespective of neuronal loss.

The apparent discrepancies between the results of the different functional and structural studies in aged animals and humans suggest considerable variability in the effects of aging on the vestibular system. One obvious explanation for this is species differences. Another possibility is that, even within a single species, some of this variability is the result of differences in a combination of genetic and environmental influences on the way that the vestibular system ages and the extent to which it is capable of adaptive plasticity in response to aging. In this respect, it is important to note that Radtke-Schuller et al. (63) have recently reported that the cholinergic vestibular efferent neurons, which provide feedback to the peripheral vestibular system, do not degenerate with age. By contrast, cochlear efferent neurons do degenerate with age.

It is reasonable to assume that functional changes in the vestibular nucleus that are associated with either vestibular impairment or plasticity that prevents it, would be the result of neurochemical changes and that these would constitute a neurochemical signature of the aged vestibular nucleus. The aim of this review is to summarize and critically evaluate what is currently known on this topic.

\section{NEUROCHEMICAL CHANGES IN THE VESTIBULAR NUCLEUS WITH AGE}

By contrast with the functional and neuroanatomical studies of the vestibular system, there are relatively few neurochemical studies of the VNC in relation to aging.

\section{Monoamines}

The VNC has been shown to receive noradrenergic inputs from the locus coeruleus and the response of VNC neurons to glutamate 
appears to be modulated by noradrenaline (NA) via $\alpha_{2}$ receptors [see Ref. $(64,65)$ for reviews]. NA also appears to modulate the response to GABA via $\alpha_{2}$ receptors and $\beta$ receptors (66). Likewise, the $\mathrm{VNC}$ receives serotonergic projections from the dorsal raphe nucleus and VNC neurons appear to have 5-hydroxytryptamine $(5-\mathrm{HT})_{1 \mathrm{~A}}, 5-\mathrm{HT}_{1 \mathrm{~B}}$, and $5-\mathrm{HT}_{2}$ receptors [see Ref. $(64,65)$ for reviews]. VNC neurons also respond to dopamine (DA) via " $\mathrm{D}_{2}$ like" receptors (i.e., $\mathrm{D}_{2}, \mathrm{D}_{3}$, and $\mathrm{D}_{4}$ receptors). There is evidence that DA depolarizes medial vestibular nucleus (MVN) neurons by acting on presynaptic " $\mathrm{D}_{2}$-like" receptors to inhibit the release of GABA from inhibitory interneurons [see Ref. (65) for a review].

Cransac et al. (67) studied the levels of NA, 5-HT, and DA and their metabolites in the MVN of rats at 4, 21, and 24 months of age, using homogenized micropunch samples and high performance liquid chromatography (HPLC). They found a decrease in NA with age and an increase in the ratio of its metabolite, 3-methoxy, 4-hydroxyphenylglycol (MHPG), to NA. By contrast, 5-HT and its metabolite, 5-hydroxyindoleacetic acid (5-HIAA), increased in the MVN with age while DA and 3,4-dihydroxyphenylacetic acid (DOPAC) levels remained unchanged. Di Mauro et al. (66) have suggested that a decrease in the NA content of the VNC could be responsible for deterioration of vestibular function with age.

\section{Amino Acids}

The excitatory and inhibitory amino acids are among the most important neurotransmitters in shaping the response of VNC neurons. Every subtype of glutamate receptor is expressed in the VNC ( $\alpha$-amino-3-hydroxy-5-methyl-4-isoxazolepropionic acid (AMPA), $N$-methyl-D-aspartate (NMDA) and the metabotropic glutamate receptors), and glutamate is the primary neurotransmitter used in the synapses between the vestibular nerve and VNC neurons [see Ref. $(64,65)$ for reviews]. Similarly, many VNC neurons have $\gamma$-aminobutyric acid (GABA) receptors of both the $\mathrm{GABA}_{\mathrm{A}}$ and $\mathrm{GABA}_{\mathrm{B}}$ subtypes, and the $\mathrm{GABA}_{\mathrm{A}}$ receptor is thought to primarily mediate commissural inhibition between the bilateral VNCs. Glycine, acting on glycine receptors, is also important in inhibitory neurotransmission in the VNC [see Ref. $(64,65)$ for reviews].

Him et al. (68) reported that the responses of MVN neurons to NMDA and AMPA were similar in brainstem slices from young (3 months of age) and aged rats (24 months of age), suggesting no change in the sensitivity of these glutamate receptor subtypes. Liu et al. (69) compared glutamate levels in the VNCs of rats at 4 and 24 months of age, using homogenized samples and HPLC, and found that glutamate levels significantly decreased with age (see Figure 1A); by contrast, there was no such decrease in the cerebellum. Since Him et al. (68) measured only the response of MVN neurons to NMDA and AMPA, and Liu et al. (69) measured only the levels of glutamate, the results of these two studies are not necessarily incompatible. For example, it is possible that AMPA and NMDA receptors upregulated or increased their sensitivity to glutamate in response to a decrease in its availability, resulting in an approximately normal response to those agonists. However, neither of these studies allows the neurochemical changes to be attributed to any specific function within the VNC. Therefore, the functional significance of these results remains unclear.

Him et al. (70) reported that neurons in the MVN from aged (24 months old) rats exhibited an increased sensitivity to the $\mathrm{GABA}_{\mathrm{A}}$ receptor agonist, muscimol, which they suggested might be a compensatory change in response to a loss of neurons within the MVN. Giardino et al. (71) detected increased levels of glutamic acid decarboxylase (GAD) in the 24-month-old rat $\mathrm{VNC}$, and concluded that this may reflect an increased synthesis of GABA in the aged VNC. However, Liu et al. (69), again using homogenized samples and HPLC, found no significant change in GABA levels in the VNC or cerebellum with aging in the rat (Figure 1B).

In the only study of age-related changes in glycine receptors in the VNC to date, Nakayama et al. (72) demonstrated a large

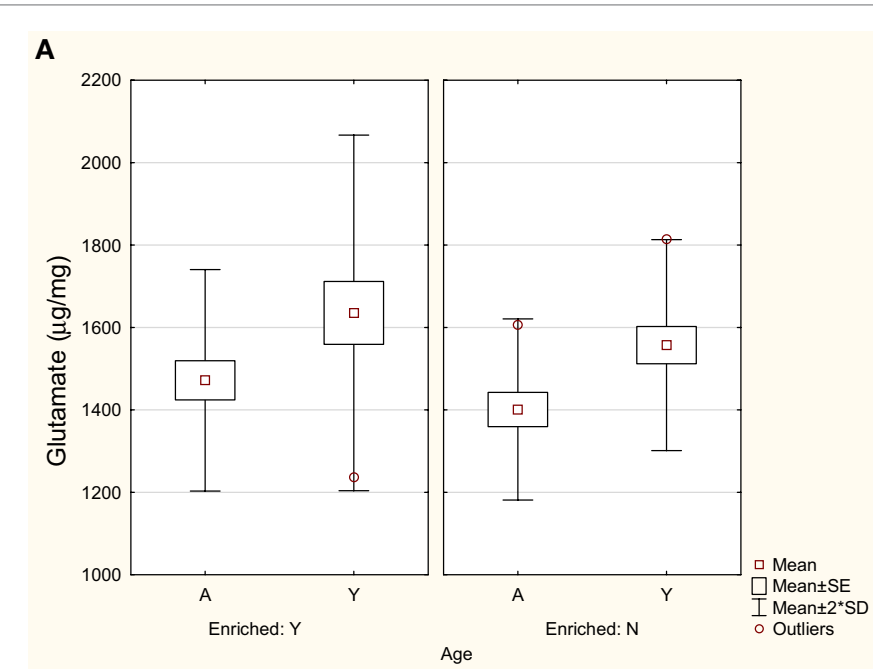

B

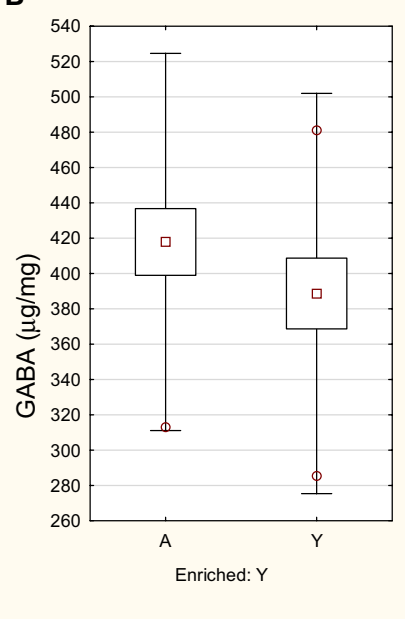

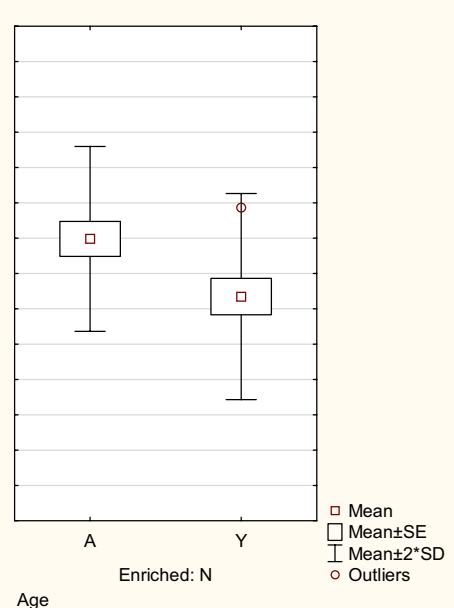

FIGURE 1 | Levels of glutamate (A) and GABA (B) in the VNC in aged (A) and young (Y) rats housed in either an enriched environment ("Y") or not ("N") Symbols represent means with the SE and SD for the mean. Modified from Liu et al. (69). 
decrease in strychnine binding in the VNC as a function of age $(3,18$, and 26 months). The amount of strychnine binding in the 26 -month-old rat was approximately $50 \%$ of that in the 3 -monthold rat. Once again, the functional significance of these changes is unknown. However, Nakayama et al. (72) speculated that an increased glycine synthesis might occur in order to prevent such a large decrease in glycine receptors from causing functional impairment.

\section{Other Neurochemical Changes with Age}

Sulaiman and Dutia (73) showed that many MVN neurons in brainstem slices are inhibited by $\delta$-opioid receptor agonists such as [D-Ala2, D-Leu5]-enkephalin (DADLE) and [D-Pen2, Pen5]enkephalin (DPLPE), an effect that was blocked by the $\delta$-receptor antagonist, naltrindole. Interestingly, they found that the inhibitory effects of DADLE increased with age, although the oldest animals used were only 160-180 g in weight.

Liu et al. (69) were interested in analyzing the L-arginine metabolic system in the VNC and cerebellum of aged (24 months old) and young (4 months old) rats. Some of the rats were housed in a standard environment, and others were housed in an enriched environment, with running wheels and toys. They employed homogenized samples, HPLC and liquid chromatography/mass spectrometry (LC/MS/MS) to quantify the concentrations of L-arginine, L-citrulline, L-ornithine, agmatine, putrescine, spermidine, spermine, as well as glutamate and GABA (the latter as previously mentioned). These neurochemicals are all related and part of the L-arginine metabolic pathway (see Figure 2). L-arginine is a semi-essential amino acid metabolized by nitric oxide synthase

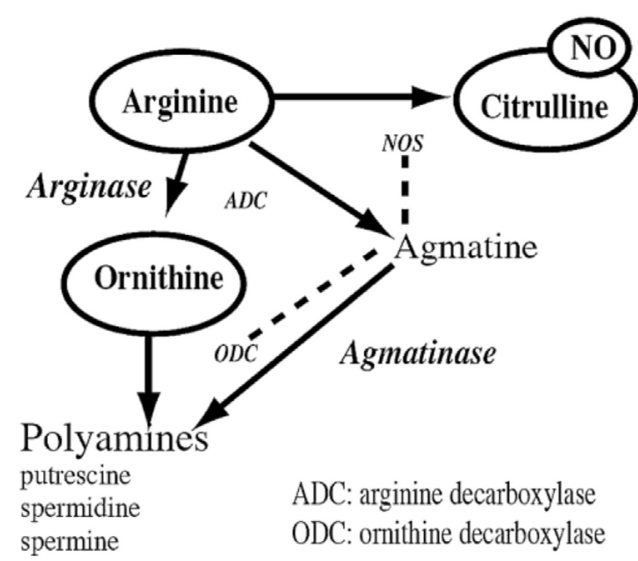

FIGURE 2 | The arginine metabolic pathway showing the conversion of L-arginine to the neurotransmitter, nitric oxide (NO), and L-citrulline, by nitric oxide synthase (NOS), of which there are three isoforms; the conversion of L-arginine to agmatine by arginine decarboxylase (ADC), which is then converted to polyamines such as putrescine, spermidine, and spermine by agmatinase and ornithine decarboxylase (ODC); and the conversion of L-arginine to L-ornithine by arginase, which is then converted to the same polyamines. Glutamate is one of the end products of L-arginine, and glutamate serves as a precursor for the synthesis of GABA. Reproduced from Smith et al. (82) with permission from Elsevier.
(NOS) in order to produce nitric oxide (NO) and L-citrulline (74). $\mathrm{NO}$ is non-conventional neurotransmitter that is important for synaptic plasticity and learning and memory; however, it is also a free radical, and therefore in excessive amounts it can be neurotoxic [see Ref. (75) for a review]. There is a great deal of evidence that NO is implicated in both the normal aging process and agerelated neurodegenerative processes $[(76,77)$; see Ref. $(78,79)$ for reviews]. The polyamines putrescine, spermidine, and spermine are down-stream metabolites of L-arginine (see Figure 2).

Liu et al. (69) found that in the VNC, putrescine, L-arginine, and L-citrulline increased significantly with age, while spermine and L-ornithine decreased (see Figure 3). In the cerebellum, spermidine and L-citrulline increased significantly with age, while spermine decreased. Linear discriminant analysis (LDA) was used to show that age could be predicted from a subset of these neurochemicals. For the VNC, the LDA could predict age with $100 \%$ accuracy from the levels of putrescine, spermidine, spermine, L-citrulline, glutamate, and GABA. For the cerebellum, age could be predicted with $93 \%$ accuracy from the levels of spermine and spermidine only.

L-citrulline (the coproduct of NO) was significantly higher in the aged VNC and cerebellum, which is consistent with the increase in $\mathrm{NO}$ in the aged cerebellum that has been reported previously (80). Mistry et al. (81) reported that L-arginine concentrations in the cerebellum were not significantly different between young (3-5 months old) and aged (18-22 months old) male rats, which is consistent with the results of Liu et al. (69).

In further analyses of the same data set, Smith et al. (82) used multiple linear regression in order to determine whether each variable could be predicted from the others. Age was a significant predictor variable for putrescine $\left(R^{2}=0.68\right)$, spermidine $\left(R^{2}=0.93\right)$, agmatine $\left(R^{2}=0.76\right)$, and L-ornithine $\left(R^{2}=0.50\right)$. Using cluster analyses, there were no large differences in the covariation of the different neurochemical variables between the young and aged animals, and glutamate and GABA covaried closely in both groups (see Figure 4).

In summary, there is evidence that, with aging, the levels of $\mathrm{NA}$ and glutamate decrease in the VNC, while those of 5-HT and NO increase (Figure 5). On the other hand, there is evidence that GABA and DA levels do not change significantly (Figure 5). The data relating to neuronal responsiveness are more difficult to interpret, since they may reflect receptor number, affinity or efficacy; however, the available data suggest that the response of VNC neurons to NMDA and AMPA receptor agonists does not change significantly, while $\mathrm{GABA}_{\mathrm{A}}$ receptor and $\delta$-opioid receptor agonists have an increased effect. There is a significant downregulation of glycine receptors in the VNC with age.

\section{CONCLUSION AND FUTURE DIRECTIONS}

Although vertigo and dizziness are common complaints among the elderly $(15,16)$, there is some disagreement as to how much of this is due to VOR dysfunction. Some recent studies have suggested that the VOR remains relatively preserved even in people over the age of 80 [e.g., Ref. (17)]. There is, on the other hand, evidence for dysfunction of $\mathrm{o}-$ and $\mathrm{c}-\mathrm{VEMPs}$ with advancing age [e.g., Ref. (19, 23-26)]. The evidence for age-related hair cell loss 

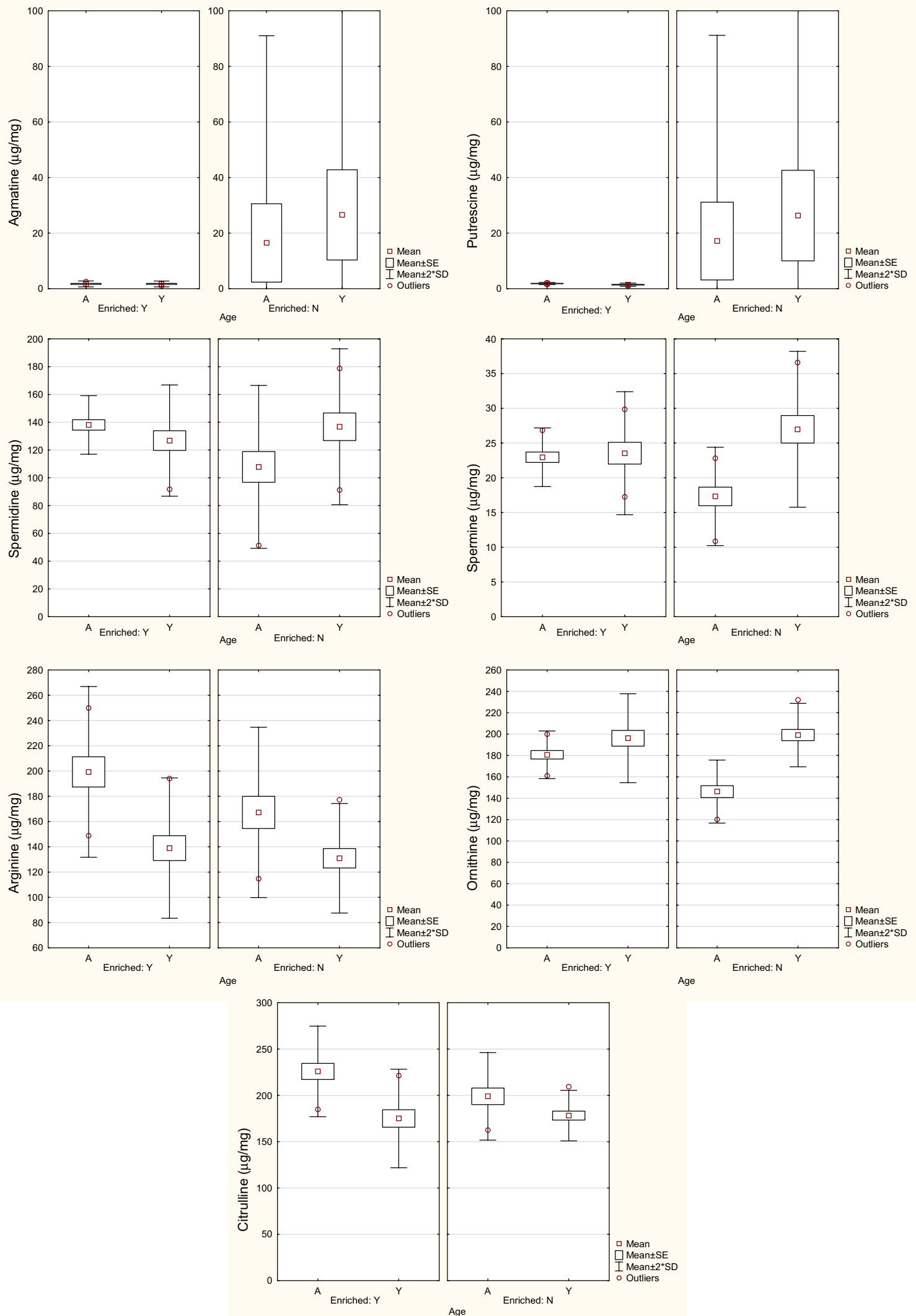

FIGURE 3 | Levels of agmatine, putrescine, spermidine, spermine, L-arginine, L-ornithine, and L-citrulline in the VNC in in aged (A) and young (Y) rats housed in either an enriched environment (Y) or not (N). Symbols represent means with the SE and SD for the mean. Modified from Liu et al. (69). 


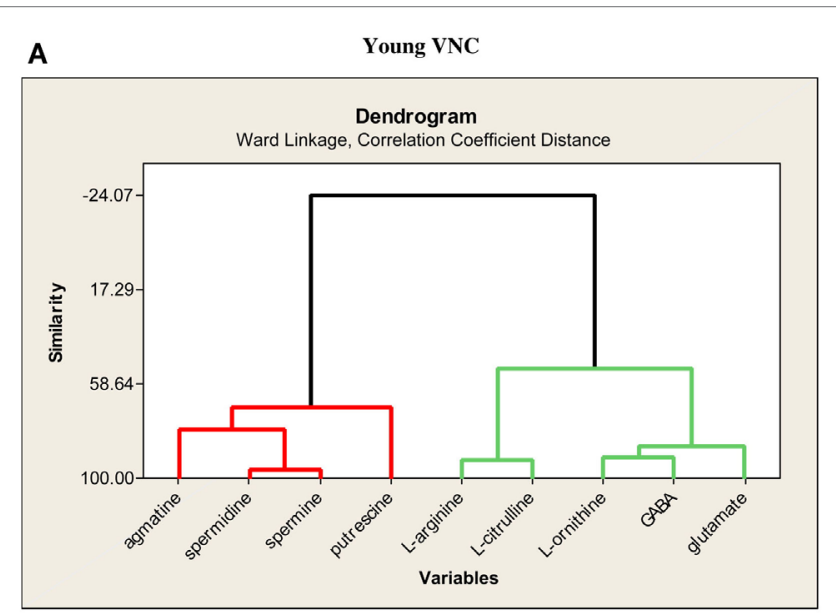

B

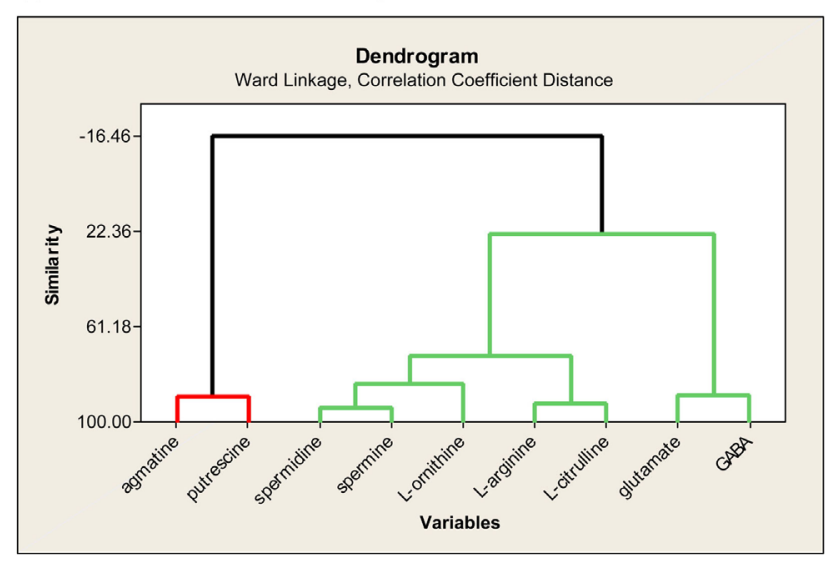

FIGURE 4 | Dendrograms showing the similarities in the degree of expression of the nine neurochemical variables in the VNC of young (A) and aged (B) rats. Reproduced from Liu et al. (69) with permission from Elsevier.

and neuronal loss in Scarpa's ganglion and the VNC is divided; however, it may be that structural deterioration occurs even without neuronal loss. One possibility is that some of the changes that lead to increased vertigo and dizziness in the elderly are related not to peripheral degeneration or even degeneration in the VNC, but to deterioration in the vestibulo-limbic and vestibulo-cortical pathways. Recent studies have shown age-related changes in the vestibulo-cortical networks and epidemiological studies have increasingly linked vestibular impairment to cognitive deficits in the elderly (29-31).

Assuming that there are structural and functional changes in VNC neurons with age that contribute to vestibular impairment, it is almost certain that these will be dictated by neurochemical changes, either causing deterioration of function or perhaps caused by that deterioration; some of these changes may even be compensatory and may help to preserve vestibular function, up to a point. Unfortunately, at this time, there are relatively few quantitative studies that can shed light on this topic. Of the studies that have been published, there is evidence for a decrease in NA and an increase in 5-HT in the VNC, with no change

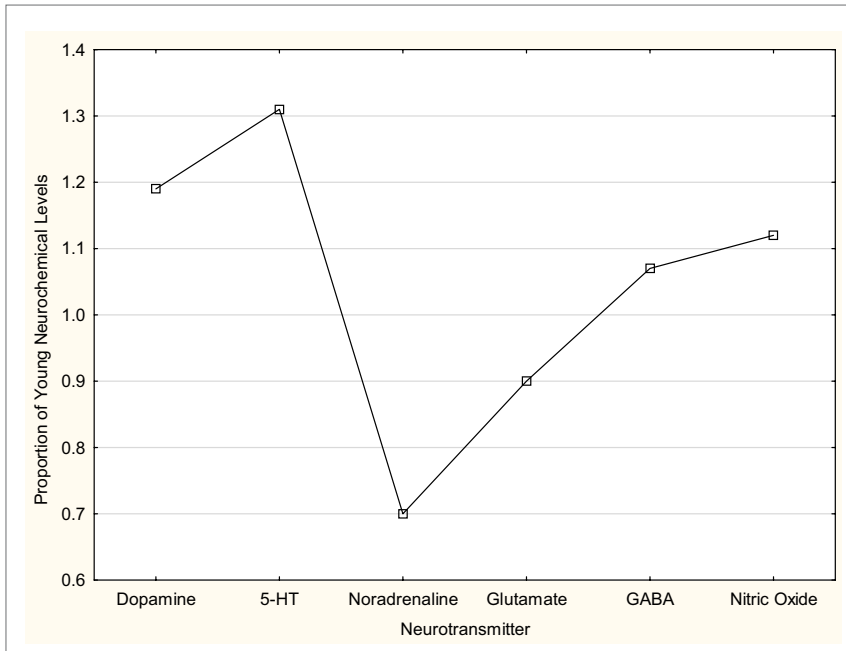

FIGURE 5 | Schematic diagram of changes in levels of dopamine, 5-HT, noradrenaline, glutamate, GABA and nitric oxide, with age. The data regarding dopamine and 5-HT are from Table 1 in Cransac et al. (67). The data regarding noradrenaline are estimated from Figure $\mathbf{1}$ in the same paper. The data regarding glutamate and GABA are from Liu et al. (69). The nitric oxide levels are estimated from the levels of the coproduct $L$-citrulline (i.e., both are produced from the action of nitric oxide synthase on L-arginine), also from Liu et al. (69). In all cases, the young data are from rats at 3-4 months of age and the aged data from animals at 24 months of age. The data from Cransac et al. (67) are from the MVN whereas the data from Liu et al. (69) are from the VNC as a whole. In all cases, the aged data are expressed as a proportion of the mean values for the young data in each study, in order to make comparisons across studies possible. The changes in 5-HT, noradrenaline, glutamate, and nitric oxide were statistically significant.

in DA levels (67); a decrease in glutamate levels (69) with no change in the sensitivity of AMPA and NMDA receptors (68) (Figure 5). The evidence relating to GABA is contradictory, with Giardino et al. (71) reporting an increase in GAD, possibly reflecting an increased synthesis of GABA, while Liu et al. (69) found no significant change in GABA levels (Figure 5). On the other hand, Him et al. (70) reported an increased sensitivity of MVN neurons to a $\mathrm{GABA}_{\mathrm{A}}$ receptor agonist. There is evidence for a decrease in glycine receptors (72) and an increase in the sensitivity of MVN neurons to the inhibitory effects of $\delta$ opioid receptor agonists (73). Finally, Liu et al. (69) have reported complex changes in various neurochemicals that are part of the $\mathrm{L}$-arginine metabolic pathway, some of which are implicated in the production of NO. Unfortunately, to completely understand the changes that are occurring in any particular neurotransmitter system, it is necessary to have information not only about neurotransmitter levels, preferably their release (see below), but also the number, affinity and efficacy of their receptors (i.e., the degree to which activation of the receptor by an agonist results in a change in neuronal function, for example, via influx of ions through linked ion channels or $G$ protein mobilization). For example, it is possible to have no change in neurotransmitter release, no change in receptor number or affinity, however a change in efficacy. While neurotransmitter release can be measured using microdialysis in vivo, and receptor number can be measured using receptor binding, western blotting or 
immunohistochemistical methods, affinity, with spatial information, is best measured using receptor autoradiography, and efficacy requires the use of patch clamping (for ion channellinked receptors) or GTPase assays (to measure G protein mobilization for $\mathrm{G}$ protein-coupled receptors). The combination of all these methods is rarely used and therefore it can be difficult to interpret the functional meaning of a decrease or an increase in a neurotransmitter without knowing the number, affinity and efficacy of the receptors.

Aside from the many differences in species and methods, e.g., different types of HPLC to analyze neurochemical levels and electrophysiological versus binding techniques to analyze receptors, most of the available studies suffer from the limitation that it is difficult, if not impossible, to relate any neurochemical changes observed to the function of specific VNC neurons (other than attributing the changes to a specific subnucleus of the VNC such as the MVN, if only that subnucleus was dissected). Furthermore, it is impossible to determine whether any observed changes are the cause of a functional deficit in the VNC as opposed to an effect of it. In fact, there are few electrophysiological studies of VNC neuronal function in aged animals. One reason for this is that aged animals are expensive and difficult to maintain for the required length of time. Twenty-two months for a rat is equivalent to approximately 65 years for a human, and therefore some animals will not survive the desired length of time. A perennial limitation of HPLC studies is that they analyze the total concentrations of neurochemicals in brain tissue, not only

\section{REFERENCES}

1. Baloh RW. Dizziness in older people. J Am Geriatr Soc (1992) 40:713-21. doi: 10.1111/j.1532-5415.1992.tb01966.x

2. Baloh RW, Enrietto J, Jacobson KM, Lin A. Age-related changes in vestibular function: a longitudinal study. Ann N Y Acad Sci (2001) 942:210-9. doi:10.11 11/j.1749-6632.2001.tb03747.x

3. BalohRW,Jacobson KM,Socotch TM. The effect of aging onvisual-vestibuloocular responses. Exp Brain Res (1993) 95:509-16. doi:10.1007/BF00227144

4. Baloh RW, Ying SH, Jacobson KM. A longitudinal study of gait and balance dysfunction in normal older people. Arch Neurol (2003) 60:835-9. doi:10.1001/ archneur.60.6.835

5. Paige GD. Senescence of human visual-vestibular interactions. 1. Vestibuloocular reflex and adaptive plasticity with aging. JVestib Res (1992) 2: $133-51$.

6. Redfern MS, Jennings JR, Martin C, Furman JM. Attention influences sensory integration for postural control in older adults. Gait Posture (2001) 14:211-6. doi:10.1016/S0966-6362(01)00144-8

7. Tian JR, Crane BT, Wiest G, Demer JL. Effect of aging on the human initial interaural linear vestibulo-ocular reflex. Exp Brain Res (2002) 145:142-9. doi:10.1007/s00221-002-1111-z

8. Su HC, Huang TW, Young YH, Cheng PW. Aging effect on vestibular evoked myogenic potential. Otol Neurotol (2004) 25:977-80. doi:10.1097/00129492-200411000-00019

9. Horak FB. Postural orientation and equilibrium: what do we need to know about neural control of balance to prevent falls? Age Ageing (2006) 35:ii7-11. doi:10.1093/ageing/afl077

10. Serrador JM, Lipsitz LA, Gopalakrishnan GS, Black FO, Wood SJ. Loss of otolith function with age is associated with increased postural sway measures. Neurosci Lett (2009) 465(1):10-5. doi:10.1016/j.neulet.2009.08.057

11. Deshpande N, Patla AE. Visual-vestibular interaction during goal directed locomotion: effects of aging and blurring vision. Exp Brain Res (2007) 176:43-53. doi:10.1007/s00221-006-0593-5 the components related to their role as neurotransmitters, and therefore some of the changes may reflect energy metabolism and any apparent lack of change may be due to adjustments in the neurotransmitter/non-neurotransmitter components (69). Therefore, one important future direction will be to combine microdialysis, which can measure neurotransmitter release within the VNC, with electrophysiological recording from single neurons. This is a much more difficult method than using brain homogenate samples, but will yield more specific information. Another important new direction will be to exploit optogenetic techniques in order to selectively modulate neuronal subtypes via light-sensitive proteins that have been genetically inserted into the target neurons (83), while at the same time using microdialysis to measure neurotransmitter release and electrophysiology to record functional changes.

\section{AUTHOR CONTRIBUTIONS}

The author confirms being the sole contributor of this work and approved it for publication.

\section{ACKNOWLEDGMENTS}

Some of the research reviewed here was supported by grants from the New Zealand Neurological Foundation and Lottery Health Board to Assoc. Prof. Ping Liu of the Department of Anatomy, University of Otago.

12. Agrawal Y, Davalos-Bichara M, Zuniga MG, Carey JP. Head impulse test abnormalities and influence on gait speed and falls in older individuals. Otol Neurotol (2013) 34(9):1729-35. doi:10.1097/MAO.0b013e318295313c

13. Agrawal Y, Zuniga MG, Davalos-Bichara M, Schubert MC, Walston JD, Hughes J, et al. Decline in semicircular canal and otolith function with age. Otol Neurotol (2012) 33(5):832-9. doi:10.1097/MAO.0b013e3182545061

14. Davalos-Bichara M, Agrawal Y. Normative results of healthy older adults on standard clinical vestibular tests. Otol Neurotol (2014) 35(2):297-300. doi:10.1097/MAO.0b013e3182a09ca8

15. Iwasaki S, Yamasoba T. Dizziness and imbalance in the elderly: age-related decline in the vestibular system. Aging Dis (2014) 6(1):38-47. doi:10.14336/ AD.2014.0128

16. Fernández L, Breinbauer HA, Delano PH. Vertigo and dizziness in the elderly. Front Neurol (2015) 6:144. doi:10.3389/fneur.2015.00144

17. McGarvie LA, MacDougall HG, Halmagyi GM, Burgess AM, Weber KP, Curthoys IS. The video head impulse test (vHIT) of semicircular canal function - age-dependent normative values of VOR gain in healthy subjects. Front Neurol (2015) 6:154. doi:10.3389/fneur.2015.00154

18. Matiño-Soler E, Esteller-More E, Martin-Sanchez JC, Martinez-Sanchez JM, Perez-Fernandez N. Normative data on angular vestibulo-ocular responses in the yaw axis measured using the video head impulse test. Otol Neurotol (2015) 36(3):466-71. doi:10.1097/MAO.0000000000000661

19. Li C, Layman AJ, Carey JP, Agrawal Y. Epidemiology of vestibular evoked myogenic potentials: data from the Baltimore longitudinal study of aging. Clin Neurophysiol (2015) 126(11):2207-15. doi:10.1016/j.clinph.2015.01.008

20. Kim JS, Sharpe JA. The vertical vestibulo-ocular reflex, and its interaction with vision during active head motion: effects of aging. J Vestib Res (2001) 11:3-12.

21. Chang NY, Hiss MM, Sanders MC, Olomu OU, MacNeilage PR, Uchanski RM, et al. Vestibular perception and the vestibulo-ocular reflex in young and older adults. Ear Hear (2014) 35(5):565-70. doi:10.1097/AUD.0000000000000052

22. Deshpande N, Tourtillott BM, Peters BT, Bloomberg JJ. Dynamic visual acuity (DVA) during locomotion for targets at near and far distances: effects of aging, 
walking speed and head-trunk coupling. J Vestib Res (2013) 23(4-5):195-201. doi:10.3233/VES-130500

23. Janky KL, Shepard N. Vestibular evoked myogenic potential (VEMP) testing: normative threshold response curves and effects of age. J Am Acad Audiol (2009) 20(8):514-22. doi:10.3766/jaaa.20.8.6

24. Akin FW, Murnane OD, Tampas JW, Clinard CG. The effect of age on the vestibular evoked myogenic potential and sternocleidomastoid muscle tonic electromyogram level. Ear Hear (2011) 32(5):617-22. doi:10.1097/ AUD.0b013e318213488e

25. Chang CM, Young YH, Cheng PW. Age-related changes in ocular vestibular-evoked myogenic potentials via galvanic vestibular stimulation and bone-conducted vibration modes. Acta Otolaryngol (2012) 132(12):1295-300. doi:10.3109/00016489.2012.708437

26. Singh NK, Kashyap RS, Supreetha L, Sahana V. Characterization of age-related changes in sacculocolic response parameters assessed by cervical vestibular evoked myogenic potentials. Eur Arch Otorhinolaryngol (2014) 271(7):186977. doi:10.1007/s00405-013-2672-0

27. Ray CA, Monahan KD. Aging attenuates the vestibulo-sympathetic reflex in humans. Circulation (2002) 105:956-61. doi:10.1161/hc0802.104289

28. Kuipers NT, Sauder CL, Ray CA. Aging attenuates the vestibulerespiratory reflex in humans. J Physiol (2003) 548:955-61. doi:10.1113/ jphysiol.2002.033357

29. Bigelow RT, Semenov YR, Trevino C, Ferrucci L, Resnick SM, Simonsick EM, et al. Association between visuospatial ability and vestibular function in the Baltimore longitudinal study of aging. J Am Geriatr Soc (2015) 63(9):1837-44. doi:10.1111/jgs.13609

30. Semenov YR, Bigelow RT, Xue QL, Lac SD, Agrawal Y. Association between vestibular and cognitive function in U.S. adults: data from the national health and nutrition examination survey. J Gerontol A Biol Sci Med Sci (2015) 71(2):243-50. doi:10.1093/gerona/glv069

31. Cyran CA, Boegle R, Stephan T, Dieterich M, Glasauer S. Age-related decline in functional connectivity of the vestibular cortical network. Brain Struct Funct (2016, in press).

32. Agrawal Y, Carey JP, Della Santina CC, Schubert MC, Minor LB. Disorders of balance and vestibular function in US adults: data from the national health and nutrition examination survey, 2001-2004. Arch Intern Med (2009) 169(10):938-44. doi:10.1001/archinternmed.2009.66

33. Brandt T, Schautzer F, Hamilton DA, Bruning R, Markowitsch H, Kalla R, et al. Vestibular loss causes hippocampal atrophy and impaired spatial memory in humans. Brain (2005) 128:2732-41. doi:10.1093/brain/awh617

34. Bigelow RT, Agrawal Y. Vestibular involvement in cognition: visuospatial ability, attention, executive function, and memory. J Vestib Res (2015) 25(2):73-89. doi:10.3233/VES-150544

35. Wallace DG, Hines DJ, Pellis SM, Whishaw IQ. Vestibular information is required for dead reckoning in the rat. J Neurosci (2002) 22(22):10009-17.

36. Zheng Y, Balabhadrapatruni S, Munn O, Masumura C, Darlington CL, Smith PF. Evidence for deficits in a 5 choice serial reaction time task in rats with bilateral vestibular deafferentation. Behav Brain Res (2009) 203:113-7. doi:10.1016/j.bbr.2009.04.027

37. Zheng Y, Darlington CL, Smith PF. Impairment and recovery on a food foraging task following unilateral vestibular deafferentation in rat. Hippocampus (2006) 16:368-78. doi:10.1002/hipo.20149

38. Zheng Y, Goddard M, Darlington CL, Smith PF. Bilateral vestibular deafferentation impairs performance in a spatial forced alternation task in rats. Hippocampus (2007) 17:253-6. doi:10.1002/hipo.20266

39. Zheng Y, Goddard M, Darlington CL, Smith PF. Long-term deficits on a foraging task after bilateral vestibular deafferentation in rats. Hippocampus (2009) 19:480-6. doi:10.1002/hipo.20533

40. Baek J-H, Zheng Y, Darlington CL, Smith PF. Evidence that spatial memory deficits in rats following bilateral vestibular loss are probably permanent. Neurobiol Learn Mem (2010) 94:402-13. doi:10.1016/j.nlm.2010.08.007

41. Gleeson M, Felix H. A comparative study of the effect of age on the human cochlear and vestibular neuroepithelia. Acta Otolaryngol Suppl (1987) 436:103-9. doi:10.3109/00016488709124982

42. Anniko M. The aging vestibular hair cell. Am J Otolaryngol (1983) 4:151-60. doi:10.1016/S0196-0709(83)80037-4
43. Lyon MJ, King JM. Aging rat vestibular ganglion: II. Quantitative electron microscopic evaluation. Ann Otol Rhinol Laryngol (1997) 106:753-8. doi:10.1177/000348949710600908

44. Merchant SN, Velazquez-Villasenor L, Tsuji K, Glynn RJ, Wall C III, Rauch SD. Temporal bone studies of the human peripheral vestibular system. Normative vestibular hair cell data. Ann Otol Rhinol Laryngol (2000) 181:3-13.

45. Park JJ, Tang Y, Lopez I, Ishiyama A. Age-related change in the number of neurons in the human vestibular ganglion. J Comp Neurol (2001) 431:437-43. doi:10.1002/1096-9861(20010319)431:4<437::AID-CNE1081>3.0.CO;2-P

46. Rauch SD, Velazquez-Villasenor L, Dimitri PS, Merchant SN. Decreasing hair cell counts in aging humans. Ann N Y Acad Sci (2001) 942:220-7. doi:10.111 1/j.1749-6632.2001.tb03748.x

47. Kevetter GA, Leonard RB. Decreased expression of calretinin and calbindin in the labyrinth of old gerbils. Brain Res (2002) 957:362-5. doi:10.1016/ S0006-8993(02)03668-5

48. Lopez I, Ishiyama G, Tang Y, Tokita J, Baloh RW, Ishiyama A. Regional estimates of hair cells and supporting cells in the human crista ampullaris. J Neurosci Res (2005) 82:421-31. doi:10.1002/jnr.20652

49. Leonard RB, Kevetter GA. Structural and functional changes in the cristae ampullares of aged gerbils. Neuroscience (2007) 147:794-802. doi:10.1016/j. neuroscience.2007.05.001

50. Taylor RR, Jagger DJ, Saeed SR, Axon P, Donnelly N, Tysome J, et al. Characterizing human vestibular sensory epithelia for experimental studies: new hair bundles on old tissue and implications for therapeutic interventions in ageing. Neurobiol Aging (2015) 36(6):2068-84. doi:10.1016/j. neurobiolaging.2015.02.013

51. Kevetter GA, Zimmerman CL, Leonard RB. Hair cell numbers do not decrease in the crista ampullaris of geriatric gerbils. J Neurosci Res (2005) 80:279-85. doi:10.1002/jnr.20451

52. Gopen Q, Lopez I, Ishiyama G, Baloh RW, Ishiyama A. Unbiased stereologic type I and type II hair cell counts in human utricular macula. Laryngoscope (2003) 113(7):1132-8. doi:10.1097/00005537-200307000-00007

53. Alidina A, Lyon MJ. Aging rat vestibular ganglion: I. Quantitative light microscopic evaluation. Am JOtolaryngol (1990) 11:174-81. doi:10.1016/0196-0709(90)90034-S

54. Fujii M, Goto N, Kikuchi K. Nerve fiber analysis and the aging process of the vestibulocochlear nerve. Ann Otol Rhinol Laryngol (1990) 99:863-70. doi:10.1177/000348949009901103

55. Lopez I, Honrubia V, Baloh RW. Aging and the human vestibular nucleus. J Vestib Res (1997) 7:77-85. doi:10.1016/S0957-4271(96)00137-1

56. AlvarezJC, DiazC, Suarez C, FernandezJA, Gonzalezdel Rey C, Navarro A, et al. Neuronal loss in human medial vestibular nucleus. Anat Rec (1998) 251:431-8. doi:10.1002/(SICI)1097-0185(199808)251:4<431::AID-AR2>3.3.CO;2-D

57. Alvarez JC, Diaz C, Suarez C, Fernandez JA, Gonzalez del Rey C, Navarro A, et al. Aging and the human vestibular nuclei: morphometric analysis. Mech Ageing Dev (2000) 114:149-72. doi:10.1016/S0047-6374(00)00098-1

58. Tang Y, Lopez I, Baloh RW. Age-related change of the neuronal number in the human medial vestibular nucleus: a stereological investigation. J Vestib Res (2001) 11:357-63.

59. Sturrock RR. Age related changes in neuron number in the mouse lateral vestibular nucleus. J Anat (1989) 166:227-32.

60. Fernandez JA, Suarez C, Navarro A, Diaz C, Alvarez JC, Gonzalez del Rey $\mathrm{C}$, et al. Aging in the vestibular nuclear complex of the male golden hamster (Mesocricetus auratus): anatomic and morphometric study. Histol Histopathol (2007) 22:855-68.

61. Johnson JE Jr, Miquel J. Fine structural changes in the lateral vestibular nucleus of aging rats. Mech Ageing Dev (1974) 3(3-4):203-24. doi:10.1016/0047-6374(74)90017-7

62. Takeuchi YK, Takeuchi IK, Murashima Y, Seto-Ohshima A. Age-related appearance of dystrophic axon terminals in cerebellar and vestibular nuclei of Mongolian gerbils. Exp Anim (1997) 46(1):59-65. doi:10.1538/expanim.46.59

63. Radtke-Schuller S, Seeler S, Grothe B. Restricted loss of olivocochlear but not vestibular efferent neurons in the senescent gerbil (Meriones unguiculatus). Front Aging Neurosci (2015) 7:4. doi:10.3389/fnagi.2015.00004

64. Smith PF, Darlington CL. Recent advances in the pharmacology of the vestibulo-ocular reflex system. Trends Pharmacol Sci (1996) 17:421-7. doi:10.1016/ S0165-6147(96)10050-X 
65. Vidal PP, Cullen K, Curthoys IS, Du Lac S, Holstein G, Idoux E, et al. Chapter 28: the vestibular system. 4th ed. In: Paxinos G, editor. The Rat Nervous System. San Diego: Academic Press (2014). p. 805-64.

66. Di Mauro M, Bronzi D, Li Volsi G, Licata F, Lombardo P, Santangelo F. Noradrenaline modulates neuronal responses to GABA in vestibular nuclei. Neuroscience (2008) 153(4):1320-31. doi:10.1016/j.neuroscience.2008.02.014

67. Cransac H, Peyrin L, Cottet-Emard JM, Farhat F, Pequiqot JM, Reber A. Aging effects on monoamines in rat medial vestibular and cochlear nuclei. Hear Res (1996) 100:150-6. doi:10.1016/0378-5955(96)00116-5

68. Him A, Guneser R, Cenqiz N, Ozturk G. Glutamate responsiveness of medial vestibular nucleus neurons in aged rats. Brain Res Bull (2010) 81:81-4. doi:10.1016/j.brainresbull.2009.07.008

69. Liu P, Zhang H, Devaraj R, Ganesalingam G, Smith PF. A multivariate analysis of the effects of aging on glutamate, GABA and arginine metabolites in the rat vestibular nucleus. Hear Res (2010) 269:122-33. doi:10.1016/j. heares.2010.06.019

70. Him A, Johntson AR, Yau JL, Seckl J, Dutia MB. Tonic activity and GABA responsiveness of medial vestibular nucleus neurons in aged rats. Neuroreport (2001) 12:3965-8. doi:10.1097/00001756-200112210-00022

71. Giardino L, Zanni M, Fernandez M, Battaglia A, Pignataro O, Calza L. Plasticity of GABA(a) system during ageing: focus on vestibular compensation and possible pharmacological intervention. Brain Res (2002) 929:76-86. doi:10.1016/S0006-8993(01)03381-9

72. Nakayama M, Caspary DM, Konrad HR, Milbrandt JC, Helfert RH. Agerelated changes in $[3 \mathrm{H}]$ strychnine binding in the vestibular nuclei of rats. Hear Res (1999) 127:103-7. doi:10.1016/S0378-5955(98)00177-4

73. Sulaiman MR, Dutia MB. Opioid inhibition of rat medial vestibular nucleus neurones in vitro and its dependence on age. Exp Brain Res (1998) 122(2):196202. doi:10.1007/s002210050507

74. Wu G, Morris SM Jr. Arginine metabolism: nitric oxide and beyond. Biochem $J$ (1998) 336:1-17. doi:10.1042/bj3360001

75. Garthwaite J. Concepts of neural nitric oxide-mediated transmission. Eur J Neurosci (2008) 27:2783-802. doi:10.1111/j.1460-9568.2008.06285.x
76. Liu P, Smith PF, Appleton I, Darlington CL, Bilkey DK. Potential involvement of NOS and arginase in age-related behavioural impairments. Exp Gerontol (2004) 39:1207-22. doi:10.1016/j.exger.2004.04.008

77. Liu P, Smith PF, Appleton I, Darlington CL, Bilkey DK. Hippocampal nitric oxide synthase and arginase and age-associated behavioral deficits. Hippocampus (2005) 15:642-55. doi:10.1002/hipo.20085

78. Malinski T. Nitric oxide and nitroxidative stress in Alzheimer's disease. J Alzheimers Dis (2007) 11:207-18.

79. McCann SM, Mastronardi C, de Laurentiis A, Rettori V. The nitric oxide theory of aging revisited. Ann N Y Acad Sci (2005) 1057:64-84. doi:10.1196/ annals. 1356.064

80. Siles E, Martínez-Lara E, Cañuelo A, Sánchez M, Hernández R, López-Ramos JC, et al. Age-related changes of the nitric oxide system in the rat brain. Brain Res (2002) 956:385-92. doi:10.1016/S0006-8993(02)03575-8

81. Mistry SK, Greenfeld Z, Morris SM Jr, Baylis C. The 'intestinal-renal' arginine biosynthetic axis in the aging rat. Mech Ageing Dev (2002) 123(8):1159-65. doi:10.1016/S0047-6374(02)00003-9

82. Smith PF, Ganesh S, Liu P. A comparison of random forest regression and multiple linear regression for prediction in neuroscience. J Neurosci Methods (2013) 220:85-91. doi:10.1016/j.jneumeth.2013.08.024

83. Packer AM, Roska B, Häusser M. Targeting neurons and photons for optogenetics. Nat Neurosci (2013) 16:805-15. doi:10.1038/nn.3427

Conflict of Interest Statement: The author declares that the research was conducted in the absence of any commercial or financial relationships that could be construed as a potential conflict of interest.

Copyright (c) 2016 Smith. This is an open-access article distributed under the terms of the Creative Commons Attribution License (CC BY). The use, distribution or reproduction in other forums is permitted, provided the original author(s) or licensor are credited and that the original publication in this journal is cited, in accordance with accepted academic practice. No use, distribution or reproduction is permitted which does not comply with these terms. 